\title{
The Effect That Project Management Certification Has on Employability: Agents' Perceptions from Spain
}

\author{
Ignacio de los Ríos-Carmenado ${ }^{1}$, José M. Díaz-Puente ${ }^{1}$, \\ and Jesús Martínez-Almela ${ }^{2}$ \\ ${ }^{1}$ Agricultural Engineering School, Technical University of Madrid, \\ Avenida Complutense S/N, 28040 Madrid, Spain \\ \{ ignacio.delosrios, jm.diazpuente\} @upm.es \\ ${ }^{2}$ Industrial Engineering School, Technical University of Valencia, \\ Camino de la Vera S/N, 46022 Valencia, Spain \\ jma@ioagroprojects.com
}

\begin{abstract}
This study analyses the effects that the project management certification has on employability. This analysis started with a participative process in which various groups of experts who are involved in the certification of people were consulted. A personal interview was carried out amongst 106 professionals - certifying bodies, training institutions, the civil service, and international organisations - and amongst professional who are certified in project management by the International Project Management Association in Spain. The results show that the certification emerges as a powerful tool for improving employability. The effects are demonstrated across two complementary aspects: internal company aspects and external aspects relating to the labour market. Finally, by compiling the different agents' opinions, a series of measures emerge for improving the accreditation processes as an employability tool and increasing the mutual learning between public and private actors.
\end{abstract}

Keywords: employability, project management, professional skills, certification systems.

\section{Introduction}

The link between training [45] accreditation of professional skills [25] and employment is a subject which has been discussed for some time; however, it is especially pertinent during times of crisis. In an economic environment with such a competitive labour market, staying in a job or finding a new job becomes of paramount importance for many people. In this context, skill-based training has emanated as a key factor for employability at an international level.

On the other hand, since the 1970s, the evolution of integrated economies and societies in the OECD has transformed life-long learning as a key objective for training and education policies. The concept of employability is often raised in international debates [41], [27] and is understood as the aptitude for working competently within a labour market [34]. Several studies have concluded that the skill 
level within the population is linked to employability and that these skills should be adapted quickly in order to respond innovatively to the structural changes that are currently being experienced. This so-called life-long learning [36] is in response to said challenge and was adopted as a political objective for the member states of the OECD in 1996 [34]. Certification systems for professional skills are seen as tools that aim to improve people's employability and learning [20]. Therefore, the concepts of life-long learning and employability are strongly linked to these systems which are focused on skills and learning from a particular job [33], [34].

Currently, there are several active certification models for personal skills —both professional and industrial - most of which are recognised internationally. In Spain there are currently five certified organisations for professional skills which are better known and more credible for the following reasons: a) their certifying bodies are internationally recognised and they apply rules at an international level; b) they are accredited by the National Accreditation Body (ENAC), according to the applicable international standard ISO/IEC 17024: 2003 and other stipulated accreditation requirements for organisations that certify people; c) they are based on models which have a voluntary element by which certain professionals improve public recognition of their skills and abilities.

In Spain there are five such certification models for professional skills which meet these three requirements. They are associated with different areas; The European Organization for Quality (EOQ), The International Project Management Association (IPMA), The Project Management Institute (PMI), People Capability Maturity Model (P-CMM), and Coaching.

This study investigates in Spain the effect that the project management certification -IPMA's universal four level certification system - has on employability. This universal system has been present in Spain since the year 2000 through AEIPRO (Asociación Española de Ingeniería de Proyectos, Spanish Association of Project Engineering) and it's Project Management Certification Body (OCDP). This study will analyse the work already carried out, as well as the results of a participative process - including interviews and surveys - carried out with all the agents who are involved in certification processes. An estimate of the effects of the project management certification (4-L-C system) is made within the professional context of Spain and partly from the point of view of the various agents involved: companies, people certification organisations, people who are certified, the civil service, international organisations and agents responsible for training. The basic terms for project management certification are derived from the ISO/IEC 17024 standard 'General requirements for bodies operating certification of persons'.

The result of the study brings together the lessons learnt regarding the project management certification and its positive results as an employability tool. The study has also been used to collate suggestions and proposals - suitable for the Spanish and international context - which help to improve the professional certification systems. These measures are primarily focused on mitigating the lack of information regarding professional certification processes, as well as the lack of integration and coordination between the different actors involved in these processes. 


\section{Method}

At a global level, the regulations for organisations that certify people emanate from the international standard for conformity assessment and general requirements [29]. This rule sets out the criteria which these certification bodies must comply with for their accreditation. One of these criteria requires the certification body to define a process for pro-actively ensuring that certified people comply with the relevant regulations for that particular certification scheme. In accordance with the international regulation, the control process can include an evaluation process, information from the relevant authorities, structured interviews, and other regular analysis mechanisms, in order to validate the results of the certification scheme [13].

This study focuses on the regulation and quality control system used by AEIPRO's Project Management Certification Body (OCDP), as a body linked to the IPMA in Spain [1]. Similarly, the research focuses on the studies carried out by the Office for Economics and Employment of the Regional Government of Madrid which it uses to improve its employment policies [44].

In this context, the methodological focus was based on the creation of a series of key questions which were answered using participative methods; direct interviews and questionnaires sent to relevant agents [37], [46]. The study relied on cooperation with Madrid's regional government and external agents belonging to various certification bodies and international organisations, the private sector, the civil service and universities. For the first time, this participative method enabled the study to be supported by all the leading figures involved in the project management skills certification system. All their knowledge, perceptions and experience was analysed and compared in the study. With this participative and pluralist approach [30], [24] it was expected that all the agents involved would benefit greatly from their participation in the evaluation work [22]. This approach also enabled the following objectives: a) take advantage of everyone's contributions and ensure that the main source of information is the knowledge and experience of the agents involved [2], [13], [39] with skill certification systems; b) facilitate the agents' learning [38] by identifying best practice and providing guidance on possible measures for perfecting these actions; c) achieve greater involvement from people [23] and improve links between agents, given that participation is such an important source of dynamics and cooperation; and d) position the analysis of the problems and the effects from the point of view of the beneficiaries of the actions.

\subsection{Sources of Information}

The investigation's methodology combined two complementary information sources. On one hand, a secondary source, consisting of information already generated by other studies, official publications, statistics from the personal [28], scientific documentation and international experiences with regards to professional skills, certification models and project management discipline [43], [47], [26], [16], [35]. On the other hand, a primary source of information, consisting of empirical knowledge based on the leading figures' experiences and perceptions. The participative methodology was supported by the five types of agent involved in the process of certifying people: a) professionals who work in companies' human resources 
departments; b) professionals who work in bodies that certify people; c) training agents; d) public sector agents and those from international organisations; and e) people certified by the project management certification system in Spain. Two participatory methods were designed - a personal interview and one questionnairewhich were sent to 106 experts and professionals. Whilst the questionnaires were completed during March and April 2009, the interviews lasted until June 2009.

Table 1. Sources of information

\begin{tabular}{llll}
\hline Method & Sources & Population & Sample \\
\hline $\begin{array}{l}\text { Interview with } \\
\text { experts }\end{array}$ & $\begin{array}{l}\text { ENAC, certification \& } \\
\text { training bodies }\end{array}$ & 65 experts & $\begin{array}{l}46 \text { experts (from businesses, } \\
\text { certification bodies, training bodies, } \\
\text { civil service and international experts }\end{array}$ \\
Questionnaire & $\begin{array}{l}\text { IPMA Certification } \\
\text { Yearbook. ODCP }\end{array}$ & $\begin{array}{l}245 \text { professionals } \\
\text { certified in Spain }\end{array}$ & 60 certified professionals \\
\hline
\end{tabular}

The first method involved personally interviewing experts. The interview script was structured in three blocks of questions which aimed to obtain opinions from three different focus points: a) skills in the labour market; b) the effects that certification has on employability; and c) the link between training-certification-employability.

The second participative method was the questionnaire for certified people, which were carried out by the Spanish Certification Body. The questionnaires sample was extracted from the professionals who have been certified by the project management 4-L-C system in Spain and appear in AEIPRO's Certification Body directory and the IPMA Certification Yearbook (IPMA, 2009). The questionnaire was designed with the cooperation of AEIPRO's Project Management Certification Body and was completed by individuals certified in Spain. People's contributions were voluntary and anonymous. The questionnaire was structured in four parts: a) the certified person's personal information; b) assessment of the general effects of certifying people; c) assessment of skills with regards to employability; d) assessment of the effects of certification at company level; and e) assessment of the effects of certification on an individual and global level.

\subsection{Verification of the Representation}

Personal Interviews with the Experts: The participative process covered all aspects of the certification process: business environment, certification bodies, training bodies, public organisations and international experts, as well as certified individuals. Faceto-face interviews were carried out with all the directors of the certification bodies of institutions that are currently accredited in Spain by the ENAC for meeting the criteria required for certifying people.

Questionnaire for certified people: A specific group of people were interviewed, all of whom are certified by AEIPRO's Project Management Certification Body. These certified professionals are people who have demonstrated their competency in project management, through an external evaluation. The distribution of the interviews by levels of certification is in Table 2 . 
Table 2. Participative methods used

\begin{tabular}{lcc}
\hline Levels of certification $^{1}$ & $\begin{array}{c}\text { \% of population } \\
\text { certified }\end{array}$ & $\begin{array}{c}\text { \% of the } \\
\text { interviews }\end{array}$ \\
\hline Certified Projects Director (Level A) & $0.5 \%$ & $2 \%$ \\
Certified Senior Project Manager (Level B) & $5 \%$ & $8 \%$ \\
Certified Project Manager (Level C) & $22 \%$ & $21 \%$ \\
Certified Project Management Associate (Level D) & $73 \%$ & $69 \%$ \\
\hline
\end{tabular}

The Project Management Certification Body (OCDP) sent this survey to 245 people, with a response rate of $24 \%$. The representativeness of the sample and the errors are acceptable from the statistical point of view, and therefore the size of the sample was not increased [12]. The professionals interviewed are all at different stages of the Project Management Certification system. The representation of the sample was analysed and compared with the percentage of certified people according to the different levels, as per IPMA's directories [28]. All the people surveyed are currently working, which demonstrates that this professional certification can guarantee ongoing employment. With regards to professional experience, $69 \%$ have over 10 years of experience, whilst $12 \%$ have less than five years of experience. This group has a mainly technical background ( $71 \%$ are engineers), although it also includes professionals with a non-technical background (29\% are graduates).

\section{Results}

\subsection{The Effects That the Project Management Certification Has on Employability}

All the experts that were interviewed across the various areas involved agree that the certification of skills is a good tool in terms of employability. 50\% of the experts that were interviewed valued the way in which the certification helps when it comes to making up for any shortfalls in employees' behavioural and contextual skills. Behavioural competences are the most highly rated by all the experts and they highlight ethics and appreciation of values as areas for improvement; these behavioural competences cover the project manager's attitudes and skills. $45 \%$ of the experts consider that the certification processes have effects on continuous development and improving employees' competitive advantage; something that is considered necessary for maintaining employability. Table 3 shows the ratings of the effects that the project management certification has on employability, according to the opinions of the certified people that were surveyed.

${ }^{1}$ Certified Projects Director (Level A): is able to direct an important portfolio or programme, an advanced level of knowledge and experience would be required; Certified Senior Project Manager (Level B): is able to manage a complex project; Certified Project Manager (Level C): is able to lead a project with limited complexity; Certified Project Management Associate (Level $D$ ): is able to apply project management knowledge when he participates in a project. 
Table 3. The effects that certification has on employability

\begin{tabular}{lccc}
\hline The effects of certification & Low & Medium & High \\
\hline Improved employee performance & $8 \%$ & $28 \%$ & $59 \%$ \\
Improved skill-based training & $8 \%$ & $36 \%$ & $51 \%$ \\
Improvements in companies' competitiveness & $10 \%$ & $33 \%$ & $51 \%$ \\
Improved career progression & $5 \%$ & $44 \%$ & $46 \%$ \\
Increase the company's credibility & $5 \%$ & $46 \%$ & $44 \%$ \\
Improved efficiency of team working & $5 \%$ & $49 \%$ & $41 \%$ \\
Improved communication & $3 \%$ & $51 \%$ & $38 \%$ \\
Improve the company's productivity & $8 \%$ & $54 \%$ & $33 \%$ \\
Improved conflict management & $5 \%$ & $59 \%$ & $31 \%$ \\
Improved employment policies & $15 \%$ & $51 \%$ & $23 \%$ \\
\hline
\end{tabular}

Note: Low (1-2), Medium (3-4) and High (5-6). Source: Survey of certified people, 2009

It is evident that as the level of responsibility increases (i.e. at higher certification levels), organisational-wide effects become most relevant, followed by the level of team working; whilst effects at an individual level become less valued. This confirms the idea that the certification culture has effects that go further than employees' personal benefits, and indeed affects the institution or company as a whole, starting with the improvements in human resources [32], [9]. Furthermore, the average global rating of the effects increases gradually as we move from the levels with least responsibility (Certified Project Management Associate) to the highest certification levels (Projects Director).

Approximately $85 \%$ of those surveyed consider - with a medium (33\%) or high $(51 \%)$ rating - that certification enables organisations to improve competitiveness (both companies and institutions). The rating for this effect increases as we move from the levels with least responsibility to the highest certification levels.

The effect that certification has in terms of an organisation's productivity is another of the most valued factors - with a medium-high rating amongst $87 \%$ of those surveyed- which indicates that professionals consider that certification represents a contribution to an organisation's performance, from the point of view of improving the efficiency and effectiveness of their workforce. Approximately $90 \%$ of those surveyed consider that certification has an important effect on the reliability of an organisation (company or institution).

In terms of personal factors, approximately $90 \%$ consider that certification plays an important part in improving personal performance within an organisation. Similarly, $90 \%$ of certified people highly rate certification in order to advance or achieve promotion, as well as for developing skills. Other positive effects of certifying people that those surveyed give a high rating to (approximately 90\%) include: effective team working, followed by improvements in communication and conflict \& crisis management. 


\subsection{The Effects That a 'Certification Culture' Has on Employability}

The general results of the participative processes demonstrate that the incorporation of an project management certification culture within companies has effects on two complementary factors with regards to employability. Firstly, there are effects that influence internal factors in terms of the employees' professional profile, which will be referred to as the effects on internal employability. Secondly, there are effects that are linked to the level of employees' competitiveness in the context of the labour market, which will be referred to as effects on external employability. Table 4 shows the global results of the ratings made by the certified professionals who were surveyed on the different effects which were considered.

Table 4. The effects that 'project management certification culture'

\begin{tabular}{lccc}
\hline \multicolumn{1}{c}{ The effects of a 'certification culture' } & Low & Average & High \\
\hline Improve training and learning processes & $5 \%$ & $49 \%$ & $41 \%$ \\
Improve public recognition for professionals & $5 \%$ & $33 \%$ & $56 \%$ \\
Progress towards an understanding of total quality & $5 \%$ & $54 \%$ & $33 \%$ \\
Improve efficiency in the civil service & $8 \%$ & $62 \%$ & $23 \%$ \\
Improve the quality of the civil service & $8 \%$ & $59 \%$ & $26 \%$ \\
Improve the management of human resources in companies & $10 \%$ & $49 \%$ & $36 \%$ \\
Enhance recruitment and selection processes & $8 \%$ & $44 \%$ & $41 \%$ \\
Improve companies' productivity & $15 \%$ & $72 \%$ & $10 \%$ \\
Improve employment policies & $10 \%$ & $56 \%$ & $23 \%$ \\
Higher expectation of employees' performance & $13 \%$ & $41 \%$ & $38 \%$ \\
Enhance international business, and relationships & $5 \%$ & $41 \%$ & $36 \%$ \\
Increase focus on consumers' rights & $15 \%$ & $46 \%$ & $18 \%$ \\
\hline
\end{tabular}

Note: Low (1-2), Medium (3-4) and High (5-6). Source: Survey of certified people, 2009

The effects that are most highly rated by certified professionals are the improvements in the recognition of professionals $(56 \%)$, followed by the improvements in training and employees' learning processes and the improvements in recruitment and selection processes. In terms of the effects that are most linked to the company or organisation, those with the highest rating (high or very high) are the improvements in recruitment and selection processes ( $85 \%$ of those interviewed), and the public recognition of professionals ( $90 \%$ of those surveyed). This can be turned into a competitive advantage for certification, given that it reduces companies' costs when recruiting and training professionals for a particular position. The certified professionals who were interviewed award a high score to the effects on improved international relationships and they link the certification with the concept of quality. This can be explained because the project management certification is endorsed by an internationally recognised model. A high percentage of the certified professionals who were interviewed $(90 \%)$ consider that certification could be an improvement 
mechanism for educational quality and training programmes; whilst $80 \%$ consider that it could be a tool for improving employment policies.

We can conclude that the certification of professional skills -project management - is seen as a strategic element for improving employability, and complements professional development for individuals and organisations. Furthermore, it establishes a link between training processes and the demands of the labour market, building a bridge between training and employment, in line with the trends of the European Higher Education Area.

\subsection{Improvements in Employability amongst Certified People}

$75 \%$ of the experts who were interviewed consider that the project management certification can improve employability for graduates; that is, their suitability with regards to meeting companies' requirements for a particular job role. These experts consider that certification can act as a mechanism for improving employability, establishing a link between training and the demands of the labour market. Nearly $85 \%$ of the people who were surveyed consider that the project management certification is a professional tool that has positive effects on their own professional career. As can be seen in Table 5, the most valued effects amongst those surveyed are the improvements in experience and knowledge, improvements to contextual skills for developing their professional activity.

Table 5. Evaluation of the effects that certification has on improving employability

\begin{tabular}{lcc}
\hline \multicolumn{1}{c}{ The effects evaluated by different professionals } & Level & Average \\
\hline Improve my knowledge and new experiences & Very High & 4.8 \\
It has allowed me to improve my behavioural skills & Very High & 4.8 \\
It has allowed me to improve my contextual skills & Very High & 4.7 \\
It has allowed me to establish new professional contacts & Very High & 4.5 \\
It is a professional development tool & Very High & 4.5 \\
It has allowed me to improve my technical skills & High & 4.3 \\
Improve the quality of project management & High & 4.2 \\
It has allowed me to increase the international work & Medium & 3.8 \\
It has helped my career progression & Medium & 3.4 \\
\hline
\end{tabular}

Note: Low (1-2), Medium (3-4) and High (5-6). Source: Survey of certified people, 2009

All of the professionals who were interviewed were already working when they became certified. As a result, the effects that the project management certification has on finding a job cannot be quantified. The effects of certification are aimed at improving both external and internal employability. Approximately $45 \%$ of those interviewed highly rate certification, as a professional development tool.

In order to evaluate the effects that certification has on employability and one's professional career, a further four criteria were considered in terms of following the certified professionals: a) new projects carried out after certification, b) new functions and responsibilities developed after certification, c) extra training carried out and, d) new experiences obtained after certification. In terms of these four criteria, a range of 
results was obtained. The majority of certified professionals (87\%) have taken on new responsibilities in new projects following on from their certification. $72 \%$ have taken on new roles and responsibilities in the project/programme/portfolio management field. $80 \%$ have improved their training since becoming certified, going on to receive further training. $21 \%$ have been involved in higher education through postgraduate study, and $36 \%$ through professional specialisation courses. Finally, $70 \%$ have increased their area of professional activity with a large range of new experiences, in particular consultancy and advisory roles, project management, teaching and research.

Participants were also asked to rate the skills they value most in terms of employability. The certified professionals who were surveyed consider that the skills that have the most influence on employability are behavioural (4.5), followed by technical (4.3), and contextual (4.1). They highlight 6 behavioural skills: ethics, compromise and motivation, leadership, conflict \& crisis management, creativity, and efficiency; and 5 "technical" skills that are strongly linked to the professional capacity for integrating social aspects in the professional arena: team working, problem resolution, relationships with interested parties, project organisation, and communication.

\section{Conclusion}

The global results and opinions of the various agents demonstrate that the project management certification is an employability tool that has an effect on two complementary factors: on internal aspects of companies and organisations (internal employability) and on external factors in relation to the labour market (external employability).

From the professional and business world, 93\% of the experts stated that the project management certification has a high usage potential as an employability tool. It is considered as an added-value tool offered to employees and companies, but at a secondary level when it comes to hiring somebody. There is still a great lack of knowledge about certification systems in the business world. The results of this study support Baker's [4] findings which state that when candidates are recruited they are evaluated through other mechanisms such as references from previous employers, psychological tests or other internal tools within the company. However, it can be seen that, in accordance with other studies [7], [14], [6] skill-based factors are considers to be important for professional performance within companies and they are considered when it comes to evaluating candidates' employability.

From within this business environment the benefits of certification which stand out the most are that it improves the company/organisations' competitiveness and it provides the employee and company with the confidence to perform well. From within this business environment it is evident that there is not a sufficient connection between training and the demands of the labour market (in accordance with the results of [6], [21]). Similarly, $75 \%$ of the experts who were interviewed consider that professionals do not meet the companies' requirements when applying for a job, whilst $50 \%$ consider that there is a shortfall in behavioural skills; as explained in a study by Cannon [10] or the Tunning Project [42]. 
Training experts agree that skills certification models such as the universal fourlevel-certification system represent a clear path between skill-based training and employability. The new context of The European Higher Education Area offers opportunities for professional skills to be included in training processes, strives to adapt to the need for comprehensive training (with values) and is orientated towards improving the employability of graduates. Certification is considered as a tool for connecting external agents (across different professional sectors) to training processes. However, for this connection to be efficient it must be accompanied by changes in learning processes (see [8]).

Experts from project management bodies in Spain, Germany, France, UK, Portugal and Switzerland consider that the model is clearly expanding and has direct, obvious effects on individuals' employability and on the companies in which the employees are based. The official figures according to the IPMA Certification Yearbook [28] show the increasing number of professionals and organizations that have become involved in these processes as a strategy for improving performance. The tracking/monitoring of certified professionals by these bodies guarantees the benefits for individuals.

International debates raise the concept of "employability", which is understood as "the aptitude for working competently within the labour market" [33]. The opinions of experts from international bodies reflect the global tendencies for promoting the integration of skills in areas such as education and work [34]. A great deal of emphasis is placed on countries designing and implementing specific strategies that allow improvements in the quality of human capital [14] and the equilibrium of everchanging labour markets.

Experts from different countries have been interviewed as well as Quality Agencies, Accreditation, Certification and Testing bodies. Generally, the responses stress the need for linking certification systems with life-long learning and redefining current policies. Amongst these replies, ideas stand out such as the need for motivating employees to gain certification, linking education, certification and employment, embedding measures for increasing the level of voluntary certification, expanding the number of certification systems and making certification systems more transparent, in accordance with international requirements.

Amongst those individuals who are certified, the most valued effect of the project management certification (in terms of employability) is the improvement in their own professional development. Approximately $85 \%$ of the professionals who were interviewed consider that the project management certification tool has an influence on improving their professional career. Furthermore, all the professionals state that the effects of certification go beyond personal benefits and impact other aspects of team working and the company/institution as a whole.

Finally, in addition to collating the opinions of the different agents, a number of proposals are also made for improving certification as an employability tool and for promoting mutual learning between public and private actors. These proposals respond to the main arguments highlighted by all the agents involved; the lack of information regarding professional certification processes (i.e. systems, benefits etc.); and the need for better integration/coordination between the different actors involved and qualification systems/certification processes. 
With regards to the lack of information available, it was stressed that there is a need for encouraging employees to become professionally certified. Some ideas are suggested, such as: promoting professional certification with assistance for unemployed professionals, help for companies to reduce the cost of certifying their professionals, or help for companies to increase training programmes which could lead to professional certification. In this respect, there was also talk of investing more resources into educational innovation targeted at gaining professional skills. It is about communicating the benefits of certification in terms of employability and creating a culture that promotes certifications with a voluntary characteristic.

As for the lack of coordination between the different actors involved, they were encouraged to create new mechanisms for linking education, certification and employment; creating strategic alliances between these actors with the purpose of improving employability; unifying evaluation processes for professional skills; diversifying systems for certifying people, increasing options, making them more transparent, in accordance with the international requirements (ISO 17024) and giving them a more progressive characteristic. There was also an emphasis on the need to improve the management of qualification systems and the link to certification systems, in order to improve the relationship between the two. There was a discussion around helping certifying bodies to supervise and monitor their certified professionals, with a view to improving their quality control systems and the way in which the certifications are used.

Until now promotion and dissemination efforts have been focused on each agent's individual initiatives, with the exception of the civil service, whose initiatives have been primarily focused on qualification systems (work skills). The previous proposals are raised in view of the need to incorporate the different agents involved in the certification process (private and public) who have participated in this study.

\section{References}

1. AEIPRO, NCB3.1: Bases para la competencia en Dirección de Proyectos. UPV-AEIPRO Traducción y Adaptación: J. Martínez-Almela (2010)

2. Argyris, C., Schön, D.: Organisational Learning: A Theory of Action Perspective. Addison Wesley, Bostan (1978)

3. Arnnold, J., Mackenzie, K.: Self-ratings and supervisor ratings of graduate employees competences during early career. Journal of Occupation and Organizational Psychology 65, 235-250 (1992)

4. Baker, B.: MCI Management Competences and APL: The way forward for Management Education, Training and Development? J. of Industrial Training 15(9), 17-26 (1991)

5. Barnard, C.: The functions of the executive. Harvard University Press, Cambridge (1968)

6. Bergenhenegouwen, G., Horn, H., Mooijman, E.: Competence development - a challenge for HUM professionals: core competences of organizations as guidelines for the development of employees. J. of European Industrial Training 29(2), 55-92 (1996)

7. Birchall, D., Hee, T., Gay, K.: Competences for international managers. Singapore Institute of Management (1982)

8. Boyatzis, R., Stubbs, E., Taylor, N.: Learning Cognitive and Emotional Intelligence Competencies Through Graduate Managemente Education. Academy of Management Learning and Education 1(2), 150-162 (2002) 
9. Brisgstock, K.: The Graduate attributes we've overlooked: enhancing graduate employability through career management skills. Higher Education Research \& Development 28(1), 31-44 (2009)

10. Cannon, F.: Business-driven management development: developing competences which drive business performance. Journal of European Industrial Training 19(2), 26-31 (1995)

11. Caupin, G., Carvalho, N.P., Alba, J.: Revalidation AEIPRO Certification. Certification Validation Management Board. In: IPMA (2009)

12. Cea, M.: Metodología cuantitativa. Estrategias y técnicas de investigación social. Madrid: Síntesis (2001)

13. Chambers, R.: Participatory rural appraisal (PRA): Analysis of experience. World Development 22(9), 1253-1268 (1994)

14. Cheetham, G., Chivers, G.: Towards a holistic model of professional competence. Journal of European Industrial Training 20(5), 20-30 (1996)

15. Cheetham, G., Chivers, G.: The reflective (and competent) practitiones: a model of professional competence which seeks to harmonise the reflective practitioner and compentence-based approaches. J. European Industrial Training 22(7), 267-276 (1998)

16. Crawford, L.H., Hobbs, J.B., Turner, J.R: Project categorization systems: aligning capability with strategy for better results. In: PMI, Upper Darby, PA (2005)

17. Day, G.: Working with the grain? Towards sustainable rural and community development. Journal of Rural Studies 14(1), 89-105 (1998)

18. Delemare, F., Winterton, J.: What is Competence? Human Resource Development International 8(1), 27-46 (2001)

19. De los Ríos, I., Cazorla, A., Díaz, J.M., Yagüe, J.L.: Project-based learning in engineering higher education: two decades of teaching competences in real environments. Procedia Social and Behavioral Sciences 2(2), 1368-1378 (2010)

20. De los Ríos-Carmenado, I., Ros, A., Ortiz, I., Fernández, A., Del Río, M., Romera, A.: Cooperative model for learning and assessment of behavioural competences in project management according to IPMA-NCB model. Selected Proceedings 13th International Congress on Project Engineering. AEIPRO. IPMA, pp. 499-512 (2010)

21. De los Ríos-Carmenado, I., Díaz-Puente, J.M., Yagüe, J.L., Romera, A., Rodriguez, F.: The integration of project management skills in postgraduate programmes. In: Selected Proceedings 14th International Congress Project Engineering. International Project Management Association, pp. 295-310 (2011)

22. Díaz-Puente, J.M., Yaguie, J.L., Afonso, A.: Building Evaluation Capacity in Spain: A Case Study of Rural Development and Empowerment in the European Union. Evaluation Review 32(5), 478-506 (2008)

23. Díaz-Puente, J.M., Cazorla, A., De los Ríos, I.: Empowering Communities through Evaluation: Some Lessons from Rural Spain. Community Development Journal 44(1), 53-67 (2009)

24. Díaz-Puente, J., Cazorla, A., De los Ríos, I.: Policy Support for the Diffusion of Innovation among SMEs: An Evaluation Study in the Spanish Region of Madrid. European Planning Studies 17(3), 365-389 (2009)

25. Fitzenberger, B., Speckesser, S.: Employment effects of the provision of specific professional skills and techniques in Germany. Empirical Economics 32, 529-573 (2007)

26. Geraldi, J., Turner, J.R., Maylor, H., Söderholm, A., Hobday, M., Brady, T.: Innovation in project management: Voices of researchers. International Journal of Project Management 26(5), 586-589 (2008) 
27. Hallier, J.: Rhetoric but whose reality? The influence of employability messages on employee mobility tactics and work group identification. International Journal of Human Resource Management 20(4), 846-868 (2009)

28. IPMA, I. P.: IPMA Certification Yearbook 2009. Editors: Werner Schmehr, Hans Knoepfel (2009)

29. ISO/IEC:17024: Conformity assessment. General requirements for bodies operating certification of persons. Switzerland International Organization for Standardization (2003)

30. Leviton, L.: Building evaluation's collective capacity. American Journal of Evaluation 22(1), 1-12 (2001)

31. Martín-Fernández, S., De los Ríos-Carmenado, I., Cazorla, A., Martinez-Falero, E.: Pilot study on the influence of stress caused by the need to combine work and family on occupational accidents in working women. Safety Science 47(2), 192-198 (2008)

32. Moreau, M., Leathwood, L.: Graduates, employment and the discourse of employability: a critical analysis. Journal of Education and Work 16(4), 305-324 (2006)

33. OECD: What Competences de we need for a successful life and a well-functioning society. OECD, Paris (2005)

34. OCDE: Sistemas de cualificaciones. Puentes para el aprendizaje a lo largo de la vida. Madrid: INCUA. OCDE (2008).

35. Ono, D.: Upgrading skills using the US Project Management Institute body of knowledge. International Journal of Project Management 13(2), 137-140 (1995)

36. Pang, M., Chua, B.-L., Chu, C.W.L.: Learning to stay ahead in an uncertain environment. International Journal of Human Resource Management 19(7), 1383-1394 (2008)

37. Patton, M.Q.: Utilization-Focused Evaluation: The New Century Text, 3rd edn. Sage, Thousand Oaks (1997)

38. Preskill, H., Torres, R.: Evaluative Inquiry for Learning in Organization. Sage Publications, Thousand Oaks (1999)

39. Rondinelli, D.A.: Development Projects as Policy Experiments: An Adaptive Approach to Development Administration. Routledge, London (1993)

40. Schkolnick, M.: Certificación por competencias como parte del sistema de protección social: la experiencia de países desarrollados y lineamientos para América Latina CEPAL. Santiago de Chile: Serie Políticas Sociales No 113, División de Desarrollo Social (2005)

41. Scholarios, D., Van der Heijden, B., Van der Schoot, E., Bozionelos, N.: Employability and the psychological contract in European ICT sector SMEs. International Journal of Human Resource Management 19(6), 1035-1055 (2008)

42. Tunning Project: Tunning Educational Structures in Europe. Bilbao: Publicaciones de la Universidad de Deusto (2006)

43. Turner, J.R.: International Project Management Association global qualification, certification and accreditation. International Journal of Project Management 14(1), 1-6 (1996)

44. UPM-Comunidad de Madrid: Modelos internacionales de certificación de competencias profesionales como herramienta de empleabilidad: aplicación a la Comunidad de Madrid. Madrid: "Panorama Laboral". Comunidad de Madrid (2009)

45. Van de Wiele, P.: The impact of training participation and training costs on firm productivity in Belgium. International Journal of Human Resource Management 21(4), 582-599 (2010)

46. Whyte, W.F.: Participatory Action Research. Sage, Newbury Park (1991)

47. Winter, M., Smith, C., Morris, P., Cicmil, S.: Directions for future research in project management: the main findings of a UK government-funded research network. International Journal of Project Management 24(8), 638-649 (2006) 